\title{
Renal tubular acidosis is highly prevalent in critically ill patients
} Richard Brunner, Andreas Drolz, Thomas-Matthias Scherzer, Katharina Staufer, Valentin Fuhrmann, Christian Zauner,
Ulrike Holzinger and Bruno Schneeweiß

\begin{abstract}
Introduction: Hyperchloremic acidosis is frequent in critically ill patients. Renal tubular acidosis (RTA) may contribute to acidemia in the state of hyperchloremic acidosis, but the prevalence of RTA has never been studied in critically ill patients. Therefore, we aimed to investigate the prevalence, type, and possible risk factors of RTA in critically ill patients using a physical-chemical approach.

Methods: This prospective, observational trial was conducted in a medical ICU of a university hospital. One hundred consecutive critically ill patients at the age $\geq 18$, expected to stay in the ICU for $\geq 24 \mathrm{~h}$, with the clinical necessity for a urinary catheter and the absence of anuria were included.

Base excess (BE) subset calculation based on a physical-chemical approach on the first 7 days after ICU admission was used to compare the effects of free water, chloride, albumin, and unmeasured anions on the standard base excess. Calculation of the urine osmolal gap (UOG) - as an approximate measure of the unmeasured urine cation $\mathrm{NH}_{4}{ }^{+}$- served as determinate between renal and extrarenal bicarbonate loss in the state of hyperchloremic acidosis.
\end{abstract}

Results: During the first week of ICU stay 43 of the patients presented with hyperchloremic acidosis on one or more

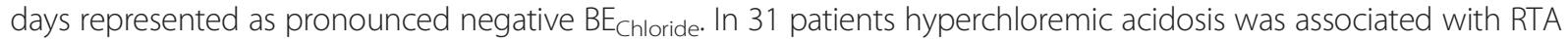
characterized by a UOG $\leq 150 \mathrm{mosmol} / \mathrm{kg}$ in combination with preserved renal function. However, in 26 of the 31 patients with RTA metabolic acidosis was neutralized by other acid-base disturbances leading to a normal arterial pH.

Conclusions: RTA is highly prevalent in critically ill patients with hyperchloremic acidosis, whereas it is often neutralized by the simultaneous occurrence of other acid-base disturbances.

Trial registration: Clinicaltrials.gov NCT02392091. Registered 17 March 2015

\section{Introduction}

Imbalances of the acid-base state and particularly metabolic acidosis are common problems in critically ill patients. To further investigate the underlying causes, analysis of the acid-base state and determination of plasma and urine electrolytes are crucial [1]. Metabolic acidosis is subdivided in conditions with either high serum anion gap (SAG) or normal SAG according to the classic model of metabolic acid-base disorders. The SAG is the difference in the measured cations $\left(\mathrm{Na}^{+}, \mathrm{K}^{+}\right)$and anions $\left(\mathrm{Cl}^{-}, \mathrm{HCO}^{3-}\right)$ in serum.

High SAG is typical for the occurrence of unmeasured anions (for example ketones, lactate, metabolites of

\footnotetext{
* Correspondence: bruno.schneeweiss@gespag.at

Department of Medicine III - Division of Gastroenterology and Hepatology,

Medical University of Vienna, Waehringer Guertel 18-20, Vienna 1090, Austria
}

methanol and ethylene glycol, phosphate) where $\mathrm{HCO}^{3-}$ is consumed via its action as a buffer. High SAG metabolic acidosis is seen in ketoacidosis, lactic acidosis, intoxication and acute renal failure [2].

Metabolic acidosis with normal SAG - hyperchloremic acidosis - is characterized by the replacement of bicarbonate with chloride caused by extrarenal or renal bicarbonate disposal or a dysfunction in renal $\mathrm{H}^{+}$secretion [1]. Hyperchloremic acidosis is typically seen in bicarbonate wasting due to diarrhea, urine-gut diversions, intestinal or pancreatic fistulae, surgical drains or renal tubular acidosis (RTA) [3].

The analysis of the urine osmolal gap (UOG) is necessary to further differentiate these conditions. The UOG represents the difference of the directly measured urine osmolality to an estimate of the urine osmolality derived 
from the urine concentrations of sodium, potassium, urea nitrogen, and glucose concentrations [4].

A UOG - as an approximate measure of unmeasured urine ammonium salts - of less than $150 \mathrm{mosmol} / \mathrm{kg}$ in combination with a preserved renal function [5] is characteristic for altered urine acidification typical for RTA [4,6], while a UOG of more than $150 \mathrm{mosmol} / \mathrm{kg}$ suggests extrarenal bicarbonate loss.

The UOG, in contrast to the urine anion gap, is not invalidated by increased excretion of unmeasured anions and therefore is the preferred measure to further analyze the causes for hyperchloremic acidosis in critically ill patients $[7,8]$.

Type 1 (distal) RTA is based on defective distal tubular $\mathrm{H}+$ secretion and is characterized by inadequately high urinary $\mathrm{pH}(>5.3)$ during hyperchloremic metabolic acidosis. In type II (proximal) RTA the underlying cause is a defect in proximal tubule bicarbonate reabsorption. This results in urinary bicarbonate loss also resulting in inappropriately high urine $\mathrm{pH}$ during hyperchloremic acidosis. However, in established type II RTA, after severe bicarbonate depletion has occurred, minimum urinary $\mathrm{pH}$ is usually below $\mathrm{pH}$ 5.3. Type IV RTA is based on mineralocorticoid deficiency or inadequate renal response to mineralocorticoids. It is characterized by low urinary $\mathrm{pH}$ and - contrary to RTA types I/II - hyperkalemia [3,9].

The prevalence of RTA and underlying metabolic changes has been studied in patients after kidney transplantation [9] and in osteoporotic patients [10]. However, studies in critically ill patients are lacking.

Based on the physical-chemical approach, more than one metabolic acid-base disorder at the same time was found to be common in critical illness [11]. Thus, 'metabolic acidosis' and 'metabolic alkalosis' may be present in the same patient at the same time, potentially leading to normal $\mathrm{pH}$ values. The terms 'acidosis' and 'alkalosis' are defined as separate effects that decrease or increase arterial $\mathrm{pH}$, respectively, whereas 'acidemia' and 'alkalemia' are defined as net arterial $\mathrm{pH}<7.35$ or $>7.45$, respectively.

Therefore, the aim of this study was to determine the prevalence of RTA in critically ill patients and to analyze the underlying acid-base state using a physical-chemical approach according to Gilfix et al. [12].

\section{Materials and methods}

\section{Patients and setting}

This prospective, observational trial was conducted in an eight-bed medical ICU at the University Hospital of Vienna, Austria between April and October 2011. One hundred consecutive critically ill patients fulfilling the inclusion criteria (age $\geq 18$, the expectancy to stay in the ICU for $\geq 24 \mathrm{~h}$, and the clinical necessity for a urinary catheter) were enrolled within 36 hours after ICU admission. Patients expected to stay $<24 \mathrm{~h}$ and anuric patients were excluded from enrollment.

Data of routinely obtained blood from arterial blood lines and urine samples were collected in all patients up to 7 days after study inclusion. Arterial blood gas analysis ( $\mathrm{pH}$, sodium, chloride, potassium, standard bicarbonate, standard base excess (SBE), $\mathrm{pCO}_{2}$, and lactate) was performed daily at 05:00 a.m. using a blood gas analyzer (ABL 725, Radiometer, Copenhagen, Denmark). At the same time, arterial plasma concentrations of albumin, creatinine, blood urea nitrogen, hemoglobin, phosphate, and magnesium, as well as spot urine concentrations of sodium, potassium, chloride, osmolality, and urine $\mathrm{pH}$ were measured at the hospital's routine laboratory using a fully automated analyzer (Hitachi 917, Roche Diagnostics $\mathrm{GmbH}$, Mannheim, Germany). Spot urine was obtained by clamping the patient's urine catheter for one hour. Subsequently, a urine sample was obtained for analysis as described above.

For every patient the following data were routinely documented: age, sex, height, weight, body mass index, admission reason and comorbidities, medication, Acute Physiology and Chronic Evaluation II (APACHE II) score, Simplified Acute Physiology Score II (SAPS II) score, Sequential Organ Failure Assessment (SOFA) score and body temperature. Heart rate, blood pressure, and urinary output were routinely documented every 4 hours and creatinine clearance was calculated every 24 hours.

The study was approved by the Ethics Committee of the Medical University of Vienna. According to the Austrian law and the guidelines of the research ethics committee, written informed consent was obtained from patients after they regained consciousness.

\section{Acid-base analysis and calculation of urine osmolal gap}

The acid-base state was analyzed using a physicalchemical approach [12]. The SBE is influenced by alterations of free water, chloride, albumin, and unmeasured anions. Therefore, SBE is composed of four subsets which were calculated as follows [11].

Base excess $(\mathrm{BE})$ caused by the free water effect:

$$
\text { Base excess }_{\text {Sodium }}=0.3 \times\left(\mathrm{Na}^{+}{ }_{\text {measured }}-\mathrm{Na}^{+}{ }_{\text {normal }}\right)
$$

The acid-base state is altered by chloride. This effect can be obtained by first correcting for changes in free water:

$$
\mathrm{Cl}^{-}{ }_{\mathrm{Na}+\text { corrected }}=\mathrm{Cl}^{-} \times\left(\left(\mathrm{Na}^{+}{ }_{\text {normal }} / \mathrm{Na}^{+} \text {measured }\right)\right)
$$

Base excess changes based on changes in chloride:

$$
\text { Base excess }{ }_{\text {Chloride }}=\mathrm{Cl}^{-} \text {normal }-\mathrm{Cl}^{-} \text {Na+corrected }
$$


Albumin is a weak non-volatile acid. The base excess effect due to albumin was calculated as:

$$
\begin{aligned}
& \text { Base excess }_{\text {Albumin }}=\left(0.148 \times \mathrm{pH}_{\text {arterial }}-0.818\right) \\
& \times\left(\text { Albumin }_{\text {normal }}-\text { Albumin }_{\text {measured }}\right) . \\
& \mathrm{Cl}^{-}{ }_{\text {normal }}=105 \mathrm{mg} / \mathrm{dL} ; \mathrm{Na}^{+}{ }_{\text {normal }}=140 \mathrm{mg} / \mathrm{dL} ; \\
& \text { Albumin }_{\text {normal }}=42 \mathrm{~g} / \mathrm{L}
\end{aligned}
$$

Further changes in base excess are based on alterations of unmeasured anions like lactate or ketone bodies. Their effect on the base excess was quantified as follows:

$$
\begin{aligned}
& \text { Base excess }{ }_{\text {unmeasured anions }} \\
& =\text { Base excess }-\left(\text { Base Excess } \text { Sodium }+ \text { Base Excess }_{\text {Chloride }}\right. \\
& + \text { Base Excess } \text { Albumin }_{\text {) }}
\end{aligned}
$$

Based on these calculations hyperchloremic acidosis was defined as: base excess attributable to changes of plasma chloride $\left(\mathrm{BE}_{\text {Chloride }}\right) \leq-5 \mathrm{mmol} / \mathrm{L}$. Hyperchloremic acidosis is characterized by extrarenal or renal bicarbonate disposal or a dysfunction in renal $\mathrm{H}^{+}$secretion. To further investigate the primary cause of hyperchloremic acidosis the UOG was calculated.

The UOG represents the difference of the directly measured urine osmolality to an estimate of the urine osmolality derived from the urine concentrations of sodium, potassium, urea nitrogen, and glucose concentrations using the following formula [4]: calculated urine osmolality $($ mosmol $/ \mathrm{kg})=\left(2 \times\left(\mathrm{Na}^{+}+\mathrm{K}^{+}\right)\right)+($urea nitrogen in $\mathrm{mg} / \mathrm{dL}$ ) $/ 2.8+$ (glucose in $\mathrm{mg} / \mathrm{dL}$ ) $/ 18$.

The UOG is an approximate measure of unmeasured urine ammonium salts, which generally are the only other major urinary solutes that contribute significantly to the urine osmolality.

The major renal response to metabolic acidosis is increased $\mathrm{NH}_{4}^{+}$excretion. Therefore, a UOG of less than $150 \mathrm{mosmol} / \mathrm{kg}$ in combination with a preserved renal function (glomerular filtration rate $>25 \mathrm{ml} / \mathrm{min}$ [5]) represents an inadequate renal response and is characteristic for RTA [4,6], while a UOG of more than $150 \mathrm{mosmol} / \mathrm{kg}$ suggests extrarenal bicarbonate loss.

Subtypes of RTA were determined as follows $[3,9]$ :

RTA type I (distal): hyperchloremic acidosis with a minimum urine $\mathrm{pH} \geq 5.3$ and low/normal plasma potassium $(<5.5 \mathrm{mmol} / \mathrm{L})$, based on reduced $\mathrm{H}^{+}$secretion in the distal tubule.

RTA type II (proximal): hyperchloremic acidosis with a minimum urine $\mathrm{pH}<5.3$ and low/normal plasma potassium $(<5.5 \mathrm{mmol} / \mathrm{L})$, based on reduced $\mathrm{HCO}^{3-}$ reabsorption in the proximal tubule.

RTA type IV: hyperchloremic acidosis with a minimum urine $\mathrm{pH}<5.3$ and high plasma potassium $(\geq 5.5 \mathrm{mmol} / \mathrm{L})$, based on reduced $\mathrm{H}^{+}$and $\mathrm{K}^{+}$excretion in the distal tubule.
Transient RTA was defined as RTA on a single study day, while persistent RTA was defined as RTA on two or more days.

\section{Objectives}

The primary objective was to evaluate the prevalence of RTA in critically ill patients during the first week after intensive care unit (ICU) admission, defined as hyperchloremic acidosis $\left.\left(\mathrm{BE}_{\text {Chloride }}\right) \leq-5 \mathrm{mmol} / \mathrm{L}\right)$, a UOG of less than $150 \mathrm{mosmol} / \mathrm{kg}$, and a preserved renal function. Secondary outcome measures were to evaluate the risk factors for RTA.

\section{Statistics}

Data are presented as mean \pm standard deviation, median $\left(25^{\text {th }}\right.$ to $75^{\text {th }}$ percentile) or absolute count and relative frequency. For bivariate comparisons, we tabulated data and used $t$ test, Mann-Whitney $U$ test, chi-squared or Fisher's exact test as appropriate to test the null hypothesis of no difference.

To assess the predictive value of potential risk factors on the incidence of RTA we performed a binary logistic regression analysis with RTA as outcome and diabetes, hypertension, congestive heart failure, chronic kidney disease, liver cirrhosis, neuroleptic drugs, muscle relaxants, combined antibiotic schemes, plasmapheresis, and sedoanalgesia, as well as age, body mass index (BMI), gender, and severity of illness (SAPS II) as co-factors.

To assess the effect of transient versus persistent RTA we conducted four multivariate regression analyses with the outcomes 'length of ICU stay', 'length of hospital stay', 'ICU survival' or 'hospital survival' and the cofactors RTA (persistent vs. transient) and 'number of study days'.

For data management and statistical analyses we used Microsoft Excel 2010 and IBM SPSS (version 20) for Windows (IBM Corp, Armonk, NY, USA).

\section{Results}

In this prospective, observational trial we included 100 critically ill patients (Table 1 ), which were evaluated daily for hyperchloremic acidosis and RTA during the first week after ICU admission. In total, 373 complete data sets each representing one patient day - derived from arterial blood and spot urine samples were analyzed.

During the first week of ICU stay 43 of the patients presented with hyperchloremic acidosis on one or more days represented as pronounced negative $\mathrm{BE}_{\text {Chloride }}$ (Figure 1). In 31 patients hyperchloremic acidosis was associated with RTA characterized by a UOG of less than $150 \mathrm{mosmol} / \mathrm{kg}$ and a preserved renal function. The majority (23 of 31) of patients with RTA presented with RTA type II, while 8 of 31 patients showed characteristics of RTA type I. However, in 26 of the 31 patients with RTA, metabolic acidosis 
Table 1 Admission reason and patients' characteristics

\begin{tabular}{|c|c|}
\hline Admission reason & $\mathrm{N}=100$ \\
\hline Respiratory failure & 31 \\
\hline St.p. Cardiopulmonary resuscitation & 21 \\
\hline Sepsis/septic shock & 8 \\
\hline Cardiogenic/hypovolemic shock & 4 \\
\hline Coma & 5 \\
\hline Esophageal/Gl bleeding & 6 \\
\hline Acute liver failure & 1 \\
\hline Intoxication & 1 \\
\hline Necrotizing pancreatitis & 1 \\
\hline Postoperative & 21 \\
\hline Diabetes mellitus & 25 \\
\hline Arterial hypertension & 41 \\
\hline Chronic renal failure & 18 \\
\hline Liver cirrhosis & 11 \\
\hline Congestive heart failure & 45 \\
\hline Acute or acute-on-chronic renal failure & 13 \\
\hline Nephrotoxic medication during study period & 93 \\
\hline Amphotericin B & 4 \\
\hline Neuroleptic drugs & 13 \\
\hline Combined antibiotic schemes & 37 \\
\hline Plasmapheresis & 3 \\
\hline Sedoanalgesia & 55 \\
\hline Muscle relaxants & 3 \\
\hline Calcineurin inhibitors & 5 \\
\hline Shock during study period & 57 \\
\hline Sepsis during study period & 42 \\
\hline Mechanical ventilation during study period & 73 \\
\hline Age (years) & $62 \pm 16$ \\
\hline Gender (female/male) & $40 / 60$ \\
\hline BMI $\left(\mathrm{kg} / \mathrm{m}^{2}\right)$ & $26 \pm 5$ \\
\hline SOFA score & $8 \pm 4$ \\
\hline APACHE I| score & $20 \pm 8$ \\
\hline SAPS II score & $51 \pm 20$ \\
\hline Length of ICU stay (days) & $6(3-11)$ \\
\hline ICU mortality (non-survivors) & 14 \\
\hline Serum creatinine $(\mathrm{mg} / \mathrm{dL})$ & $1.42 \pm 0.88$ \\
\hline Blood urea nitrogen ${ }^{*}(\mathrm{mg} / \mathrm{dL})$ & $30 \pm 22$ \\
\hline Serum uric acid* (mg/dL) & $5.2 \pm 2.5$ \\
\hline Serum phosphate $(\mathrm{mg} / \mathrm{dL})$ & $1.12 \pm 0.37$ \\
\hline Arterial $\mathrm{pH}^{*}$ & $7.37 \pm 0.09$ \\
\hline Standard bicarbonate $(\mathrm{mmol} / \mathrm{L})$ & $24.8 \pm 4.7$ \\
\hline Serum anion gap ${ }^{*}(\mathrm{mmol} / \mathrm{L})$ & $11 \pm 3.7$ \\
\hline
\end{tabular}

Table 1 Admission reason and patients' characteristics (Continued)

\begin{tabular}{ll}
\hline Urine anion gap $^{*}(\mathrm{mmol} / \mathrm{L})$ & $43 \pm 42$ \\
Creatinine clearance $^{\#}(\mathrm{~mL} / \mathrm{min})$ & $66(33-108)$ \\
Urine volume $^{\#}$ (in $\left.24 \mathrm{~h}\right)$ & $1550(920-2720)$
\end{tabular}

Data are means \pm standard deviation (SD), median $\left(25^{\text {th }}\right.$ to $75^{\text {th }}$ percentile) or absolute counts; "At ICU admission; "average of 373 patient days. Gl, gastrointestinal; BMI, body mass index; SOFA, Sequential Organ Failure Assessment; APACHE II, Acute Physiology and Chronic Evaluation II; SAPS II, Simplified Acute Physiology Score II; ICU, intensive care unit.

was neutralized mainly by simultaneously decreased plasma albumin leading to a neutral arterial $\mathrm{pH}$ (Figures 1 and 2). Moreover, these 26 patients were more ventilated in comparison to the five patients with RTA and acidemia $\left(\mathrm{pCO}_{2} 38 \pm 4\right.$ vs. $\left.46 \pm 5 \mathrm{mmHg} ; P<0.001\right)$ also contributing to a neutral arterial $\mathrm{pH}$.

Bicarbonate loss was more pronounced in RTA type II in comparison to RTA type I: RTA type II vs. RTA type I SBC 23.9 (22.6 to 25.4 ) vs. 26 (23.9 to 27) $\mathrm{mmol} / \mathrm{L} ; P=0.004$.

Of the 31 patients with RTA 18 presented with transient RTA and 13 with persistent RTA. The variable transient vs. persistent RTA was not significantly associated with the clinical outcomes 'length of ICU stay', 'length of hospital stay', 'ICU survival' or 'hospital survival'.

There were no statistical differences between patients with and without RTA in terms of age, gender, BMI, severity of disease, ICU or hospital outcome, and length of ICU or hospital stay (Table 2).

Similarly, in the multivariate analysis with RTA as outcome and diabetes, hypertension, chronic kidney disease, congestive heart failure, liver cirrhosis, neuroleptic drugs, muscle relaxants, combined antibiotic schemes, plasmapheresis, and sedoanalgesia, as well as age, BMI, gender, and severity of illness (SAPS II) as co-factors no variables were predictive for the presence of RTA.

\section{Discussion}

Hyperchloremic metabolic acidosis is a frequent entity in critically ill patients [13]. Therefore, we aimed to identify the underlying acid-base imbalances with a particular focus on RTA. As the occurrence of more than one acid-base disturbance at the same time is common in critically ill patients [11] our analysis was based on calculating the base excess subsets according to the physical-chemical approach by Gilfix et al. [12].

Forty-three percent of the patients presented at least on one day with hyperchloremic acidosis during the first week of ICU stay [13]. This is more frequent compared to Gunnerson et al. who found hyperchloremic acidosis in only $26 \%$ of critically ill patients. However, they did not determine base excess subsets. Therefore, they could not detect hyperchloremic acidosis in the state of normal 


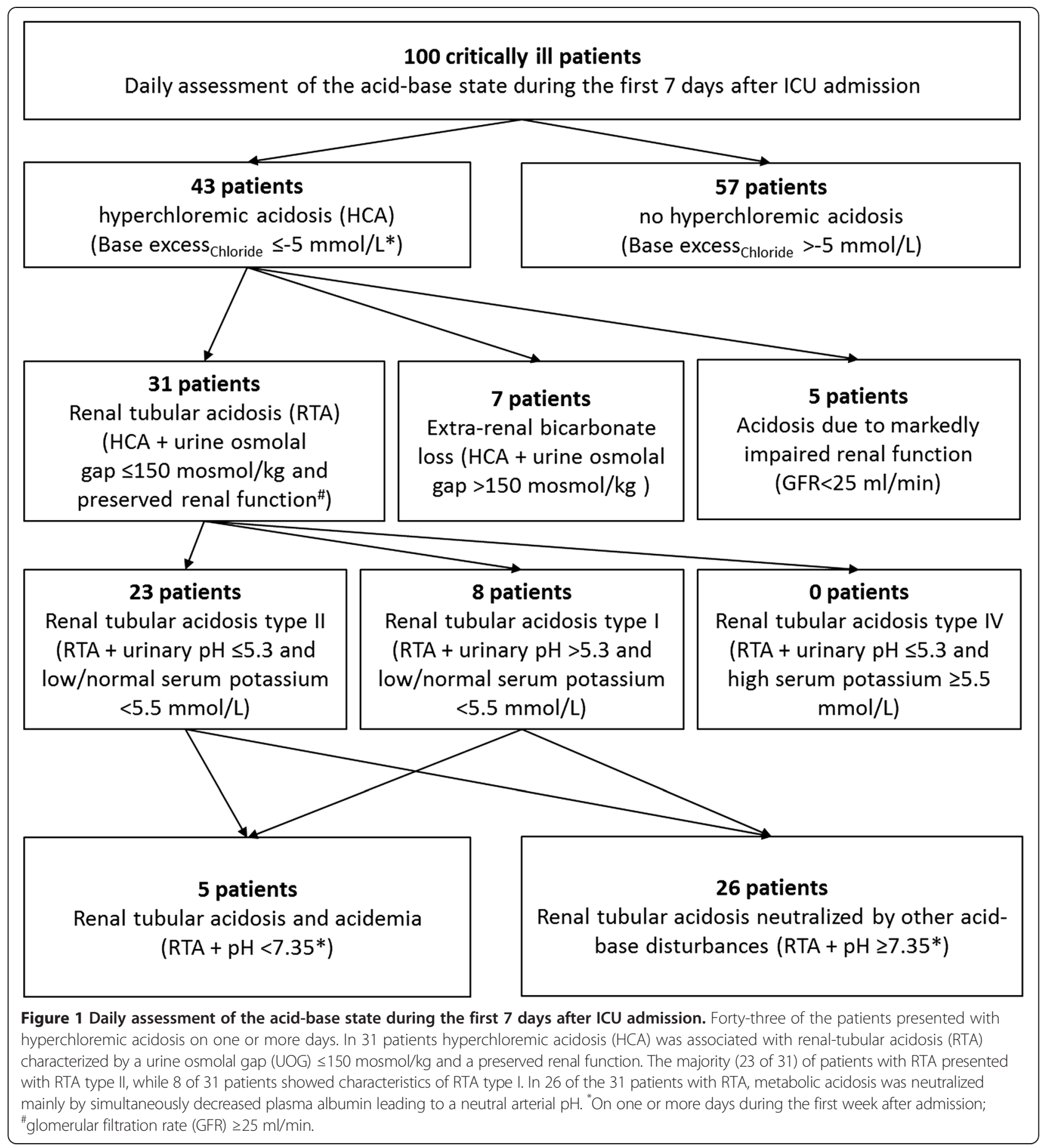

arterial $\mathrm{pH}$ values, which therefore was probably underrepresented [14].

Hyperchloremic metabolic acidosis was frequently neutralized by the simultaneous occurrence of metabolic alkalosis leading to a neutral arterial $\mathrm{pH}$ in our patients. The neutralizing effect is mainly attributed to decreased plasma albumin levels resulting in a positive base excess attributable to changes of plasma albumin $\left(\mathrm{BE}_{\mathrm{Albumin}}\right)$.
The ubiquitous occurrence of hypoalbuminemia in critically ill patients is not seen as counterregulation but is based on the albumin loss due to third space losses, plasma dilution or reduced hepatic production (negative acute phase response) [15-17].

The finding of positive $\mathrm{BE}_{\mathrm{Albumin}}$ in a large number of the included patients is compatible with the study of Funk et al. [11]. The second neutralizing effect was 


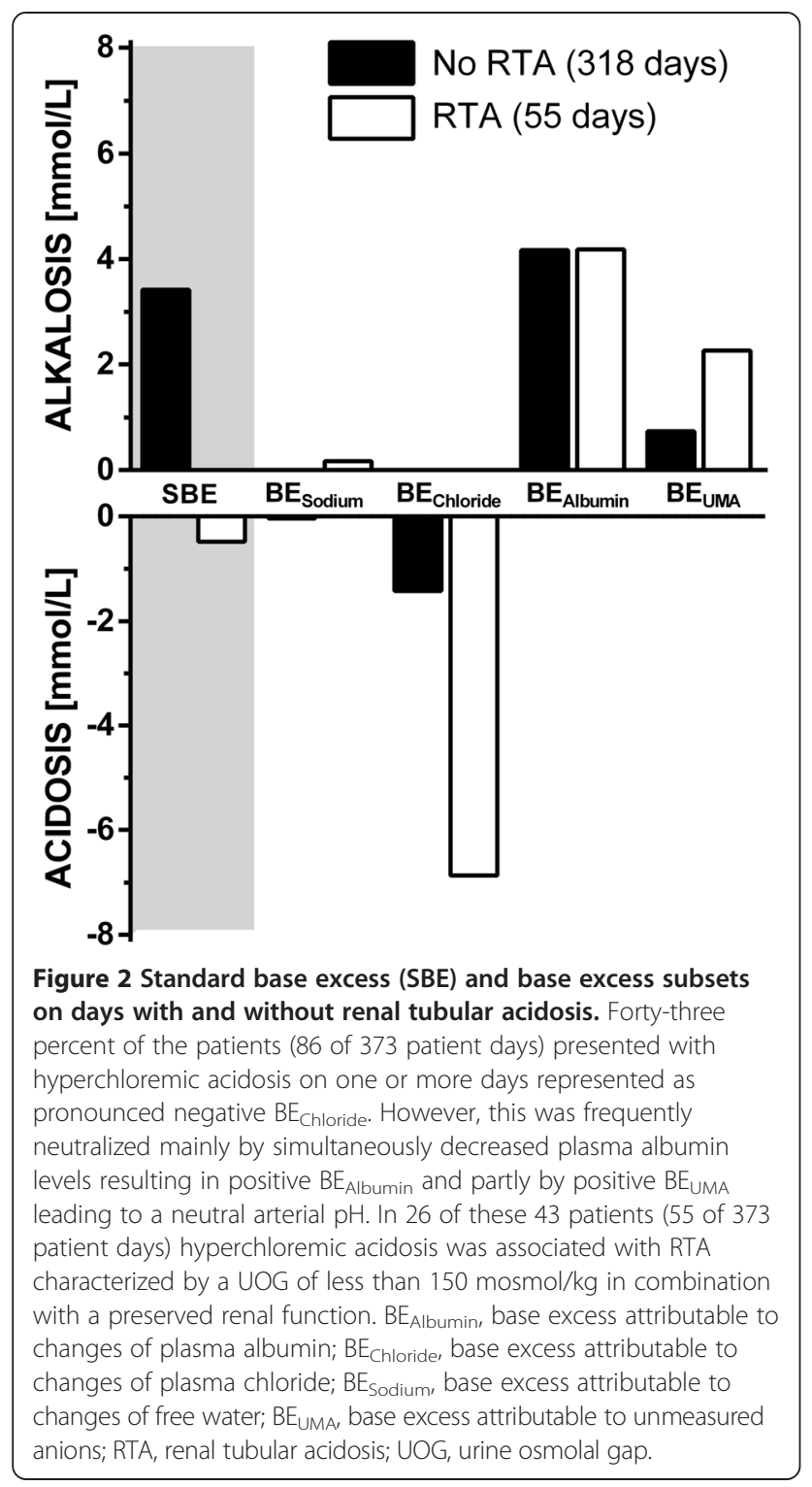

based on increased base excess attributable to unmeasured anions $\left(\mathrm{BE}_{\mathrm{UMA}}\right)$. The increased $\mathrm{BE}_{\mathrm{UMA}}$ as seen in our model of acid-base analysis is in theory either caused by an increase in unmeasured cations or a decrease in unmeasured anions. However, our finding of a mildly elevated $\mathrm{BE}_{\mathrm{UMA}}$ in the 'No RTA' group is compatible with the positive $\mathrm{BE}_{\mathrm{UMA}}$ found in healthy subjects [18]. Therefore, we assume this deviation is caused by a model artifact and the true normal value of $\mathrm{BE}_{\mathrm{UMA}}$ is $+1 \mathrm{mmol} / \mathrm{L}$ [11]. However, in the 'RTA' group $\mathrm{BE}_{\mathrm{UMA}}$ was significantly higher in comparison to the 'No RTA' group, which can only be explained by the presence of unmeasured cations in patients with RTA. This phenomenon has also been seen in the literature and may be due to the accumulation of guanidines, lithium intoxications, or paraproteinemias with positively charged
Table 2 Comparison of demographic and outcome parameters between patients with renal tubular acidosis on one or more days compared to patients without renal tubular acidosis

\begin{tabular}{llll}
\hline & $\begin{array}{l}\text { No RTA } \\
(\mathbf{n}=69)\end{array}$ & $\begin{array}{l}\text { RTA } \\
(\mathbf{n}=\mathbf{3 1})\end{array}$ & $\boldsymbol{P}$ value \\
\hline Age (years) & $63 \pm 16$ & $60 \pm 17$ & 0.862 \\
Gender (female/male) & $(28 / 41)$ & $(12 / 19)$ & 1.000 \\
BMI (kg/m²) & $26 \pm 5$ & $27 \pm 4$ & 0.409 \\
SOFA score on admission & $8 \pm 4$ & $9 \pm 4$ & 0.696 \\
APACHE II score on admission & $20 \pm 9$ & $19 \pm 8$ & 0.224 \\
SAPS II score on admission & $51 \pm 20$ & $52 \pm 20$ & 0.837 \\
Length of ICU stay (days) & $5(3-11)$ & $8(5-11)$ & 0.157 \\
Length of hospital stay (days) & $13(6-22)$ & $16(8-33)$ & 0.371 \\
ICU mortality (non-survivors [\%]) & $16 \%$ & $10 \%$ & 0.404 \\
Hospital mortality (non-survivors [\%]) & $30 \%$ & $19 \%$ & 0.332 \\
$\begin{array}{l}\text { Deceased within 7 day observation } \\
\text { period }\end{array}$ & $10 \%$ & $6 \%$ & 0.717 \\
\hline
\end{tabular}

Data are means \pm standard deviation (SD), median $\left(25^{\text {th }}\right.$ to $75^{\text {th }}$ percentile) or absolute counts. RTA, renal tubular acidosis; BMI, body mass index; SOFA, Sequential Organ Failure Assessment; APACHE II, Acute Physiology and Chronic Evaluation II; SAPS II, Simplified Acute Physiology Score II; ICU, intensive care unit.

gammaglobulins [19]. Similarly to Mallet et al., the type and origin of unmeasured cations in the RTA group remain open.

To determine the prevalence of RTA we first selected patients with hyperchloremic acidosis (43 of 100 patients; Figure 1). Thirty-one of this subgroup presented with a UOG of less than $150 \mathrm{mosmol} / \mathrm{kg}$ in combination with preserved renal function [5], which is characteristic for RTA (Figure 1). Thus, our data show for the first time that RTA was highly prevalent in critically ill patients with hyperchloremic acidosis, which is suggestive that RTA contributes to the pathophysiology of hyperchloremic acidosis in these patients.

Acidemia (arterial $\mathrm{pH}<7.35$ ) is associated with unfavorable outcome in critically ill patients, which may be pronounced by RTA $[14,20]$. However, hyperchloremic acidemia is suggested to be less detrimental than lactic or ketoacidemia [21]. Moreover, although there is strong evidence of the association between acidosis and poor outcome in critically ill patients, there is little evidence of causation. Mild (hyperchloremic) acidosis may even be a physiological response as oxygen delivery is enhanced via the Bohr effect [22].

In the present trial, RTA in combination with hyperchloremic acidosis was not associated with the outcome parameters lengths of ICU or hospital stay and ICU or hospital mortality.

Therefore, we hypothesize that RTA in combination with hyperchloremic acidosis in the present study is not a harmful condition, but may be a physiological response 
in the presence of several metabolic acid-base disorders at the same time (Figure 2).

Hyperchloremic acidosis is attributed to several causes. On the one hand, extrarenal bicarbonate loss may be based on diarrhea or via surgical drains. This is defined as a UOG of more than $150 \mathrm{mosmol} / \mathrm{kg}$ and was observed in $16 \%$ of the patients with hyperchloremic acidosis (7 of 43) in the present study (Figure 1). Markedly decreased renal function (glomerular filtration rate $<25 \mathrm{ml} / \mathrm{min}$ [5]) as a potential contributing factor to metabolic acidosis was seen in 12\% (5 of 43) of the patients with hyperchloremic acidosis (Figure 1).

Parenterally administered solutions with unphysiologically high chloride content may contribute to hyperchloremic acidosis. This was observed in patients after rapid isotonic saline infusion while undergoing a surgical procedure [23]. Although 'isotonic' saline was not used in this study for volume resuscitation, patients may have received it prior to ICU admission. Furthermore, antibiotics and parenteral nutrition contain certain amounts of chloride. On average the amount of sodium chloride applied via medication and parenteral nutrition was rather low and not different between patients with and without RTA (Table 3).

However, despite the significantly increased blood chloride levels in patient samples with RTA, urine chloride levels were not elevated (Table 3). This suggests an

Table 3 Comparison of biochemical parameters on days with and without renal tubular acidosis

\begin{tabular}{llll}
\hline & $\begin{array}{l}\text { No RTA } \\
\text { (318 days) }\end{array}$ & $\begin{array}{l}\text { RTA } \\
\text { (55 days) }\end{array}$ & P value \\
\hline Arterial pH & $7.41 \pm 0.07$ & $7.40 \pm 0.19$ & 0.421 \\
$\mathrm{pCO}_{2}$ & $45.3 \pm 13.1$ & $39.2 \pm 4.9$ & $<0.001$ \\
Standard bicarbonate (mmol/L) & $27 \pm 5$ & $24 \pm 2$ & $<0.001$ \\
Standard base excess (mmol/L) & $3.4 \pm 5.1$ & $-0.48 \pm 3.51$ & $<0.001$ \\
$\quad \mathrm{BE}_{\text {Sodium }}(\mathrm{mmol} / \mathrm{L})$ & $0.0 \pm 1.4$ & $0.2 \pm 1.2$ & 0.317 \\
$\quad \mathrm{BE}_{\text {Chloride }}(\mathrm{mmol} / \mathrm{L})$ & $-1.4 \pm 4.1$ & $-6.9 \pm 1.5$ & $<0.001$ \\
$\quad \mathrm{BE}_{\text {Albumin }}(\mathrm{mmol} / \mathrm{L})$ & $4.2 \pm 1.2$ & $4.2 \pm 1.0$ & 0.969 \\
$\quad \mathrm{BE}_{\text {Uum }}(\mathrm{mmol} / \mathrm{L})$ & $0.7 \pm 2.9$ & $2.3 \pm 2.0$ & $<0.001$ \\
Serum sodium $(\mathrm{mmol} / \mathrm{L})$ & $140 \pm 5$ & $141 \pm 4$ & 0.317 \\
Serum potassium $(\mathrm{mmol} / \mathrm{L})$ & $4.1 \pm 0.5$ & $4.1 \pm 0.4$ & 0.894 \\
Serum chloride $(\mathrm{mmol} / \mathrm{L})$ & $106 \pm 5$ & $112 \pm 3$ & $<0.001$ \\
Serum phosphate $(\mathrm{mmol} / \mathrm{L})$ & $0.97 \pm 0.36$ & $0.89 \pm 0.28$ & 0.121 \\
Serum lactate $(\mathrm{mmol} / \mathrm{L})$ & $1.4 \pm 0.9$ & $1.2 \pm 0.6$ & 0.319 \\
Urine chloride $(\mathrm{mmol} / \mathrm{L})$ & $80 \pm 42$ & $83 \pm 45$ & 0.163 \\
Creatinine clearance $(\mathrm{mL} / \mathrm{min})$ & $63(26-106)$ & $83(46-125)$ & 0.786 \\
NaCl 0.9\% infusion per day $(\mathrm{mL})$ & $250(10-550)$ & $300(114-857)$ & 0.268 \\
\hline
\end{tabular}

Data are means \pm standard deviation (SD), median $\left(25^{\text {th }}\right.$ to $75^{\text {th }}$ percentile) or absolute counts. RTA, renal tubular acidosis; $\mathrm{BE}_{\text {Sodium, }}$, base excess attributable to changes of free water; $\mathrm{BE}_{\mathrm{Chloride}}$, base excess attributable to changes of plasma chloride; $\mathrm{BE}_{\text {Albumin, }}$ base excess attributable to changes of plasma albumin; $\mathrm{BE}_{\mathrm{UMA}}$, base excess attributable to unmeasured anions. altered renal chloride handling as seen in RTA rather than external chloride administration.

Hyperchloremia per se is known to cause gastrointestinal symptoms, reduced renal blood flow and glomerular filtration rate, as well as coagulation disorders [22]. Whereas coagulation disorders and gastrointestinal symptoms were not studied in the present trial, hyperchloremic acidosis per se - independent of the resulting arterial $\mathrm{pH}$ - was not associated with decreased glomerular filtration rate or with increased length of stay or mortality (data not shown).

Ammonium chloride-loading/frusemide tests and the bicarbonate-loading test are the golden standards to distinguish between proximal and distal RTA in noncritically ill patients [3]. However, due to potential gastrointestinal, renal, and respiratory side effects of these drugs we decided to use a non-invasive approach based on urinary $\mathrm{pH}$ and urinary potassium [9].

A potential weakness of our study is the use of the UOG as a surrogate for urinary ammonium concentrations. However, the direct measurement of urinary ammonium was not routinely available in our hospital [24].

Another weakness of the present trial is that it was only a single-center observation with all its known limitations [25].

Moreover, the findings derived from our study are only associative and are, therefore, naturally only hypothesis generating.

To compensate for shortcomings in the present trial, we suggest that future trials should be conducted in a multicenter setting, should be based on direct measurement of urinary ammonia, should also focus on unmeasured cations, and should prospectively collect data on multiorgan dysfunction, effectiveness of therapies administered, and neurological/cardiac performance.

Hypoalbuminemia is ubiquitous in critically ill patients represented by positive $\mathrm{BE}_{\text {Albumin }}$. Thus, RTA - in the presence of normal arterial $\mathrm{pH}$ - may be a physiological response and the result of the counterregulation of metabolic alkalosis due to low albumin levels.

\section{Conclusions}

RTA is highly prevalent in critically ill patients with hyperchloremic acidosis, whereas it is often neutralized by the simultaneous occurrence of other acid-base disturbances.

\section{Key messages}

- Hyperchloremic acidosis and renal tubular acidosis are highly prevalent in critically ill patients

- The simultaneous occurrence of multiple acid-base disturbances at the same time in the same patient is common in the critically ill 


\section{Abbreviations}

APACHE II: Acute Physiology and Chronic Evaluation II; BE: base excess; $B E_{A l b u m i n}$ : base excess attributable to changes of plasma albumin; $\mathrm{BE}_{\text {Chloride: }}$ base excess attributable to changes of plasma chloride; BEsodium: base excess attributable to changes of free water; BEuma: base excess attributable to unmeasured anions; BMI: body mass index: GFR: glomerular filtration rate; HCA: hyperchloremic acidosis; ICU: intensive care unit; RTA: renal tubular acidosis; SAG: serum anion gap; SAPS II: Simplified Acute Physiology Score II; SBE: standard base excess; SOFA: Sequential Organ Failure Assessment; UOG: urine osmolal gap.

\section{Competing interests}

The authors declare that there are no conflicts of interest to disclose. The study was approved by the ethics committee of the Medical University of Vienna and was conducted according to the Helsinki Declaration. All persons designated as authors have participated sufficiently in the conception and design of this work or the analysis and interpretation of the data, as well as the writing of the manuscript

\section{Authors' contributions}

RB collected data, carried out the statistical analyses and interpretations, and drafted the manuscript. RB, AD, TS, KS, VF, CZ and UH screened/enrolled patients and made substantial contributions to acquisition of data. BS made substantial contributions to the conception and design of the study. BS and $\mathrm{UH}$ helped to draft the manuscript. All authors revised the manuscript critically and approved the final version.

\section{Acknowledgements}

We thank all health professionals of the $\mathrm{ICU} 13 \mathrm{H} 1$ for their commitment to this study, as well as Dr Helen Owen for proofreading the manuscript.

Received: 14 November 2014 Accepted: 18 March 2015

Published online: 06 April 2015

\section{References}

1. Koch SM, Taylor RW. Chloride ion in intensive care medicine. Crit Care Med. 1992;20:227-40

2. Forni LG, McKinnon W, Hilton PJ. Unmeasured anions in metabolic acidosis: unravelling the mystery. Crit Care. 2006;10:220.

3. Laing CM, Unwin RJ. Renal tubular acidosis. J Nephrol. 2006;19:46-52.

4. Dyck RF, Asthana S, Kalra J, West ML, Massey KL. A modification of the urine osmolal gap: an improved method for estimating urine ammonium. Am J Nephrol. 1990;10:359-62.

5. Kraut JA, Kurtz I. Metabolic acidosis of CKD: diagnosis, clinical characteristics, and treatment. Am J Kidney Dis. 2005;45:978-93.

6. Kim GH, Han JS, Kim YS, Joo KW, Kim S, Lee JS. Evaluation of urine acidification by urine anion gap and urine osmolal gap in chronic metabolic acidosis. Am J Kidney Dis. 1996;27:42-7.

7. Halperin ML, Vasuvattakul S, Bayoumi A. A modified classification of metabolic acidosis: a pathophysiologic approach. Nephron. 1992;60:129-33.

8. Carlisle EJ, Donnelly SM, Vasuvattakul S, Kamel KS, Tobe S, Halperin ML. Glue-sniffing and distal renal tubular acidosis: sticking to the facts. J Am Soc Nephrol. 1991;1:1019-27.

9. Kocyigit I, Unal A, Kavuncuoglu F, Sipahioglu MH, Tokgoz B, Oymak O, et al. Renal tubular acidosis in renal transplantation recipients. Ren Fail. 2010;32:687-90.

10. Weger W, Kotanko P, Weger M, Deutschmann H, Skrabal F. Prevalence and characterization of renal tubular acidosis in patients with osteopenia and osteoporosis and in non-porotic controls. Nephrol Dial Transplant. 2000;15:975-80.

11. Funk GC, Doberer D, Heinze G, Madl C, Holzinger U, Schneeweiss B. Changes of serum chloride and metabolic acid-base state in critical illness. Anaesthesia. 2004;59:1111-5.

12. Gilfix BM, Bique M, Magder S. A physical chemical approach to the analysis of acid-base balance in the clinical setting. J Crit Care. 1993;8:187-97.

13. Moviat M, van Haren F, van der Hoeven $\mathrm{H}$. Conventional or physicochemical approach in intensive care unit patients with metabolic acidosis. Crit Care. 2003:7:41-5.

14. Gunnerson KJ, Saul M, He S, Kellum JA. Lactate versus non-lactate metabolic acidosis: a retrospective outcome evaluation of critically ill patients. Crit Care. 2006;10:R22.
15. Fend V, Jabor A, Kazda A, Figge J. Diagnosis of metabolic acid-base disturbances in critically ill patients. Am J Respir Crit Care Med. 2000;162:2246-51.

16. Wilkes P. Hypoproteinemia, strong-ion difference, and acid-base status in critically ill patients. J Appl Physiol. 1998;84:1740-8.

17. Blunt MC, Nicholson JP, Park GR. Serum albumin and colloid osmotic pressure in survivors and nonsurvivors of prolonged critical illness. Anaesthesia. 1998;53:755-61.

18. Funk G-C, Doberer D, Fuhrmann V, Holzinger U, Kitzberger R, Kneidinger $\mathrm{N}$, et al. The acidifying effect of lactate is neutralized by the alkalinizing effect of hypoalbuminemia in non-paracetamol-induced acute liver failure. J Hepatol. 2006:45:387-92.

19. Mallat J, Barrailler S, Lemyze M, Pepy F, Gasan G, Tronchon L, et al. Use of sodium-chloride difference and corrected anion gap as surrogates of Stewart variables in critically ill patients. PLoS One. 2013;8:e56635.

20. Dunham CM, Siegel JH, Weireter L, Fabian M, Goodarzi S, Guadalupi P, et al. Oxygen debt and metabolic acidemia as quantitative predictors of mortality and the severity of the ischemic insult in hemorrhagic shock. Crit Care Med. 1991;19:231-43.

21. Brill SA, Stewart TR, Brundage SI, Schreiber MA. Base deficit does not predict mortality when secondary to hyperchloremic acidosis. Shock. 2002;17:459-62.

22. Handy JM, Soni N. Physiological effects of hyperchloraemia and acidosis. Br J Anaesth. 2008;101:141-50.

23. Scheingraber S, Rehm M, Sehmisch C, Finsterer U. Rapid saline infusion produces hyperchloremic acidosis in patients undergoing gynecologic surgery. Anesthesiology. 1999;90:1265-70.

24. Ha LY, Chiu WW, Davidson JS. Direct urine ammonium measurement: time to discard urine anion and osmolar gaps. Ann Clin Biochem. 2012;49:606-8.

25. Bellomo R, Warrillow SJ, Reade MC. Why we should be wary of single-center trials. Crit Care Med. 2009;37:3114-9.

\section{Submit your next manuscript to BioMed Central and take full advantage of:}

- Convenient online submission

- Thorough peer review

- No space constraints or color figure charges

- Immediate publication on acceptance

- Inclusion in PubMed, CAS, Scopus and Google Scholar

- Research which is freely available for redistribution

Submit your manuscript at www.biomedcentral.com/submit
C) Biomed Central 